\title{
Developing a Model for the Establishment of Pre-Hospital Emergency Medicine Bases in the Northern Provinces of Iran
}

\author{
Azadeh Ahmadi Dashtiyan ${ }^{1}$, Iravan Masoudi Asl ${ }^{2}$,Leila Riahi ${ }^{3}$, Mahmood Mahmoodi 4 \\ PhD Candidate, Department of Health Sciences Administration, Science and Research Branch, Islamic Azad University, Tehran, Iran \\ Associate Professor, PhD of Health Services Management, Department of Health Services Management, School of Health \\ Management and Information Sciences, Iran University of Medical Sciences, Tehran, Iran \\ Assistant Professor, Department of Health Sciences Administration, Science and Research Branch, Islamic Azad University, \\ Tehran, Iran \\ 4 Professor, Department of Health Sciences Administration, Science and Research Branch, Islamic Azad University, Tehran, Iran
}

\begin{abstract}
BACKGROUND: The faster and more accurately Pre-Hospital Emergency Medicine as the first line of care and treatment is done, the less the mortality and disability rates are. AIM: The present study is an attempt to design a model for the establishment of pre-hospital emergency bases in the northern provinces of Iran.

METHODS: This quantitative-qualitative (mixed-method) research was conducted in two parts: First, using the literature review, interviews with experts in the field, and a comparative study, the most important factors affecting the establishment were extracted. Second, the obtained data were employed to formulate the development model and to design the questionnaire. The required data for factor analysis were collected through a questionnaire distributed among 200 operational personnel in January 2018. The results were analyzed using confirmatory factor analysis and multiple regression.

RESULTS: Five components were identified after the exploratory factor analysis and Varimax with an eigenvalue larger than 1 . The effect coefficients calculated for human resources components, service speed, and information and communication system were $0.935,0.765$ and 0.752 , respectively. The obtained goodness of fit was very close to one, indicating the one-dimensional strength of the model. The highest parameter estimation in this model was allocated to the human component as 0.935 , which has a significant correlation with other components.

CONCLUSIONS: In order to reduce the response time, more attention should be paid to the allocation of budget and organizational roles, education, participation from government departments, establishment of an independent medical emergency organization, and appropriate accessibility to reduce the rates of mortality and morbidity.
\end{abstract}

\section{Keywords}

Pre-hospital Emergency care, Pre-hospital, Iran

\section{INTRODUCTION}

The faster and more accurately pre-hospital emergency medicine as the first line of care and treatment is done, the less the mortality and disability rates are. It is one of the most important parts of the National Accident and Emergency Management Center of Iran, which provides health services in emergencies, accidents and injuries. Today, emergency management is one of the critical issues in the health system and is an integral component of the health care system, which operates under life-threatening conditions for the rapid care and transmission of patients and reduces the mortality rate. It is of utmost importance, then, that it complies with national standard protocols. Accidents and injuries annually cause more than 5 million deaths and more than 100 million disabilities around the world. Inadvertent accidents are the second leading cause of mortality in Iran, with an annual death toll of 28,000, the highest death toll from road accidents in the world. According to the statistics provided in Iran, every nineteen minutes a person loses his/her life due to road accidents. Poisoning, falling, drowning and burn are, respectively, the following causes of death due to inadvertent incidents [1]. According to the National Census of Population and Housing in 2011, about 930 deaths per Dashtiyan.a.a@gmail.com 
day occur in all age groups in Iran. Death due to injury is the second cause of death with about $20 \%$ of all deaths after cardiovascular disease $(46 \%) .17 \%$ of deaths are attributable to uninvited injuries, with traffic accidents ( $8 \%$ ) on top, and $3 \%$ of injuries due to intentional accidents [2]. Moreover, about $50 \%$ of deaths in traffic accidents occur during the first hour after the accidents, $25 \%$ of which during the transfer of the injured to a hospital, and $25 \%$ due to infections caused by complications in hospitals [3]. Since land transportation covers a large part of journeys to a hospital, promoting safety in these routes is vital. One of the consequences of safety impairment is traffic accidents which are expected to be the third leading cause of the global burden of diseases and injuries in 2020, due to the growing number of traffic accidents in the world [4]. Therefore, it is important to note that pre-hospital emergency is an essential component of the patients' fate, and taking into account the correct location of the bases, their development and equipment as well as desirable and professional performance are crucial measures. The results of a study on emergency patients show that the most serious errors have been observed in preventable cases, such as delay in primary care, lack of adequate care in patient transfer, and inappropriate communication [5]. In some countries, paramedical and ambulance personnel are only used to transfer patients to health centers, and no therapeutic measures are taken until patients arrive at medical centers [6]. According to the results of a study, emergency transport medical issues are an important barrier to care, and this may be due to lack of proper facilities as well as inadequate roads and transportation. Many factors, such as skilled staff, the speed of service delivery, and ambulance equipment are involved in the quality of the emergency services provided. In addition, the location of the bases is also an effective item to improve the quality of assistance to incidents and the injured [7].

Al-Shaqsi et al. [8] studied the pre-hospital emergency condition in Oman. In this country, the system is based on the Anglo-American method and medical technicians are run by the Omani police. In this study, the present situation is addressed and the effective components in the emergency performance (i.e. training, transportation, human resources, communications, and organization) are studied in detail. Bayrami et al. [9] conducted a qualitative study on fourteen base personnel selected via a purposive sampling method using a semistructured interviewing technique, and analyzed three main components of human resources challenges (personal characteristics, human forces, and staff dissatisfaction), organizational challenges (structure, lack of equipment, shortage of human resources), and socio-cultural challenges (environmental, social, and cultural). They concluded that dissatisfaction, structural challenges, lack of equipment, shortage of human forces, and socio-cultural challenges were the most important challenges of the pre-hospital emergency system. Rösler et al. [10] conducted a study in Germany and showed that the pre-hospital emergency system is tremendously efficient. Additionally, he indicated that the number of hospitals has declined because of the reduced health care costs. In addition, the number of vehicles equipped with physicians is declining as well. In this study, the effective components of emergency services including structure, transportation, human resources, communication and education of care models are described well. In 2006, Hessamuddin et al. [11] studied the management and planning system, communication systems, lack of integration of therapeutic protocols, and education in Malaysia. This study showed that the interest in pre-hospital emergency has increased and coordinated. In addition, the services provided by this section have developed day by day and simultaneously the care quality has increased [11]. In 2017, Mohammadi et al. [12] conducted a comparative study on the developed countries and found out that in many countries the shortage of financial resources in pre-hospital emergency and emergency medical services is an important barrier to the provision of services in this area. The results showed that, emergency financing is far from the desirability level in Iran. As a result, in order to meet the expectations of patients requiring emergency care, there needs to be a reform in the emergency services which requires reorganizing and revisiting planning and financial management [12].

The northern provinces of Iran are located somewhere that connects west and east of the country. Featuring forests, beautiful nature ranges, hinterland areas, coastal areas, mountainous roads and bends, these provinces attract a large number of tourists (floating population). In addition, having roads to the capital and connecting to the center of the country has made them some of the most populated provinces. The existing infrastructures such as roads, communication centers, etc. are not responsive to high traffic in these provinces and, additionally, they are designed according to the principles and rules of many years ago. Large and crowded cities, high traffic volume, numerous villages, high mountains on the sidelines, population growth, highway accidents are, therefore, highlights of the pre-hospital emergency situation in this area [13]. Since pre-hospital emergency can play a major role in decreasing mortality 
and morbidity rates, the present study attempts to design a model for the establishment of prehospital emergency bases in the northern provinces of Iran.

Using structural equation modeling for component weights and the multi-criteria decisionmaking method, the present study is innovative in methodology and tries to develop a model for the establishment of pre-hospital emergency bases in terms of management. Considering all factors affecting deployment, this model not only reduces the length of services but also provides a framework for policymakers and planners in this area.

\section{METHODS}

This study was conducted through a mixed-method research approach in 2018. In the first stage, a review of literature and library studies were done. By reviewing literature and theoretical foundations, Persian and English journals and books, scientific and research articles, dissertations, as well as resources and internal and external databases such as Science Direct, ISI, PubMed, Scopus, Elsevier, interviews, and comparative investigations, 30 subcomponents affecting the establishment of pre-hospital emergency bases were determined. Interviews with 10 experts of medical emergency management with 96 questions, as well as comparative investigation on 5 countries (USA, UK, France, Malaysia, and Germany) were conducted (Table I). The output of this research stage was the extraction of 57 items affecting the establishment of pre-hospital emergency bases. Data collection was continued in the interview section until saturation stage. The interview data were analyzed following the content analysis method. Subsequently, the data of this stage were classified by a comparative matrix. The data were repeatedly deleted and finally, the main components of the program were set up with 57 items. In the second stage, for final confirmation of the items and the main components, the expert panel including 10 faculty members in related fields and the managers of the headquarters of emergency medical centers was set, and the questionnaire was evaluated by experts. Ultimately, 30 variables remained and the final framework of the questionnaire was formed. The Cronbach's alpha method was employed to determine the questionnaire reliability by distributing copies of the questionnaire among 30 members of the research population. Then the correlation between their viewpoints was examined, and Cronbach's alpha coefficient was obtained as 0.872 . The validity of the questionnaire was also confirmed by the experts of this area. In the next stage, copies of the questionnaire were randomly distributed among participants of the study consisted of operational personnel of the Center for Accident and Emergency Medicine in Northern provinces of Iran. The sample size was estimated based on 200 participants. Sampling was done using the simple random sampling based on five to ten times the number of items on the questionnaire. The sample size was measured using the Kaiser-Meyer-Olkin (KMO) as 0.882 . The collected data were analyzed through exploratory factor analysis and after Varimax rotation, 5 main components with eigenvalues higher than 1 were obtained. In the next step, the confirmatory factor analysis method was used to validate the model and extract the final model. This analysis was performed via SPSS AMOS 22 (IBM) software. In confirmatory factor analysis, the X2 indices, significant level, relative X2, Root Mean Square Error of Approximation (RMSEA), the Normed Fit Index (NFI), and Parsimony-adjusted Comparative Fit Index (PCFI) were used to fit the model. The relationship between each component was determined as the independent variable, and the mechanism of establishment of pre-hospital emergency bases were determined as the dependent variable. The internal consistency of the dimensions was calculated using the Cronbach's alpha coefficient. In the present study, the sample group was justified and the confidentiality was observed in the process of selecting and attracting participants.

\section{RESULTS}

Over the past few years, pre-hospital emergency has been successful and pre-hospital emergency services have improved in the short term in some countries. For example, Malaysia has succeeded to improve pre-hospital emergency in a short term, and the United States has worked well on regulatory, planning, and standards. In different investigations, the study countries were very much involved with the planning component. Regarding regulations, some countries were transient and some others were concerned with details. Regarding the components of education, human resources, and communications, the selected countries also had some characteristics. In Iran, in addition to components of regulations in the organization criteria, accessibility to the speed of service, and organizational independence, the component of planning of other criteria has been taken into consideration. This indicates that the criteria 


\begin{tabular}{|c|c|c|c|c|c|c|}
\hline No. & 1 & 2 & 3 & 4 & 5 & 6 \\
\hline Models & USA & Malaysia & France & Germany & UK & Iran \\
\hline \multicolumn{7}{|l|}{ Planning } \\
\hline Financial planning and budget & $\sqrt{ }$ & $\sqrt{ }$ & $\sqrt{ }$ & $\sqrt{ }$ & $\sqrt{ }$ & $\sqrt{ }$ \\
\hline Presence of the charities & $\sqrt{ }$ & $\sqrt{ }$ & - & $\sqrt{ }$ & $\sqrt{ }$ & $\sqrt{ }$ \\
\hline EMS as an independent organization & $\sqrt{ }$ & $\sqrt{ }$ & $\sqrt{ }$ & $\sqrt{ }$ & $\sqrt{ }$ & - \\
\hline \multicolumn{7}{|l|}{ Organizing } \\
\hline Emergency standards & $\sqrt{ }$ & $\sqrt{ }$ & $\sqrt{ }$ & $\sqrt{ }$ & $\sqrt{ }$ & $\sqrt{ }$ \\
\hline Safety regulations & $\sqrt{ }$ & $\sqrt{ }$ & $\sqrt{ }$ & $\sqrt{ }$ & $\sqrt{ }$ & - \\
\hline task description & $\sqrt{ }$ & $\sqrt{ }$ & $\sqrt{ }$ & $\sqrt{ }$ & $\sqrt{ }$ & $\sqrt{ }$ \\
\hline \multicolumn{7}{|l|}{ Human resources } \\
\hline Care model & $\sqrt{ }$ & $\sqrt{ }$ & $\sqrt{ }$ & $\sqrt{ }$ & $\sqrt{ }$ & $\sqrt{ }$ \\
\hline Developed education & $\sqrt{ }$ & $\sqrt{ }$ & $\sqrt{ }$ & $\sqrt{ }$ & - & $\sqrt{ }$ \\
\hline Academic education & $\sqrt{ }$ & $\sqrt{ }$ & $\sqrt{ }$ & $\sqrt{ }$ & - & $\sqrt{ }$ \\
\hline \multicolumn{7}{|l|}{ Service speed } \\
\hline Population & $\sqrt{ }$ & $\sqrt{ }$ & $\sqrt{ }$ & $\sqrt{ }$ & $\sqrt{ }$ & $\sqrt{ }$ \\
\hline Accessibility & $\sqrt{ }$ & $\sqrt{ }$ & $\sqrt{ }$ & $\sqrt{ }$ & $\sqrt{ }$ & - \\
\hline Traffic & $\sqrt{ }$ & $\sqrt{ }$ & $\sqrt{ }$ & $\sqrt{ }$ & $\sqrt{ }$ & $\sqrt{ }$ \\
\hline \multicolumn{7}{|l|}{ Communication and information } \\
\hline Communication equipment & $\sqrt{ }$ & - & $\sqrt{ }$ & $\sqrt{ }$ & $\sqrt{ }$ & $\sqrt{ }$ \\
\hline Reporting & $\sqrt{ }$ & $\sqrt{ }$ & $\sqrt{ }$ & $\sqrt{ }$ & $\sqrt{ }$ & $\sqrt{ }$ \\
\hline Transportation system & $\sqrt{ }$ & $\sqrt{ }$ & $\sqrt{ }$ & $\sqrt{ }$ & $\sqrt{ }$ & $\sqrt{ }$ \\
\hline
\end{tabular}

Table I. Comparison of the components related to the establishment of pre-hospital emergency bases in different countries

\begin{tabular}{lc}
\hline \multicolumn{1}{c}{ Components } & Cronbach's alpha \\
\hline Planning & 0.695 \\
Organization & 0.868 \\
Human resources & 0.790 \\
Service speed & 0.750 \\
Communication and information & 0.686 \\
Total & 0.872 \\
\hline
\end{tabular}

Table II. Cronbach's alpha reliability coefficient of the components effective on the establishment of pre-hospital emergency bases in Iran are very similar to those of the selected countries (Table I).

By reviewing literature and interviews, 30 subcomponents affecting the establishment of pre-hospital emergency bases were determined. Subcomponents were confirmed by the study experts.

Among 200 participants, $86 \%$ (172 participants) were male and $14 \%$ (28 participants) were female. The highest age group (44\%) was between 31 and 40 years old. Regarding the education level, $20 \%$ (40 participants) held associate diploma and lower, 59.5\% (119 participants) held $\mathrm{BA} / \mathrm{BSc}, 15.5 \%$ (31 participants) held $\mathrm{MA} / \mathrm{MSc}$, and the rest held $\mathrm{PhD}, \mathrm{MD}$, and degrees in Medical Specialties. Based on the research results, five factors affecting the establishment of pre-hospital emergency bases in Northern provinces of Iran (planning, service speed, communication and information, organization, and human resources) were extracted via the exploratory factor analysis technique.

Reliability of the items was evaluated using Cronbach's alpha reliability coefficient. The details for each component are presented in Table II.

\begin{tabular}{|c|c|c|c|c|c|c|c|c|c|}
\hline \multirow{2}{*}{ Component } & \multicolumn{3}{|c|}{ Initial eigenvalues } & \multicolumn{3}{|c|}{$\begin{array}{l}\text { Extraction sums of squared } \\
\text { loadings }\end{array}$} & \multicolumn{3}{|c|}{$\begin{array}{c}\text { Rotation sums of squared } \\
\text { loadings }\end{array}$} \\
\hline & Total & $\begin{array}{l}\text { Variance } \\
(\%)\end{array}$ & $\begin{array}{c}\text { Cumulative } \\
\text { (\%) }\end{array}$ & Total & $\begin{array}{l}\text { Variance } \\
(\%)\end{array}$ & $\begin{array}{l}\text { Cumulative } \\
\text { (\%) }\end{array}$ & Total & $\begin{array}{l}\text { Variance } \\
(\%)\end{array}$ & $\begin{array}{l}\text { Cumulative } \\
\text { (\%) }\end{array}$ \\
\hline 1 & 6.656 & 18.183 & 18.183 & 6.656 & 18.183 & 18.183 & 4.542 & 16.627 & 16.627 \\
\hline 2 & 4.195 & 13.491 & 31.674 & 4.195 & 13.491 & 31.674 & 2.802 & 12.941 & 29.568 \\
\hline 3 & 2.110 & 11.835 & 43.509 & 2.110 & 11.835 & 43.509 & 2.429 & 10.976 & 40.544 \\
\hline 4 & 1.396 & 8.655 & 52.164 & 1.396 & 8.655 & 52.164 & 2.354 & 8.868 & 49.412 \\
\hline 5 & 1.052 & 4.494 & 56.658 & 1.052 & 4.494 & 56.658 & 2.042 & 7.246 & 56.658 \\
\hline
\end{tabular}

Table III. The total variance of 30 variables in 5 exploratory factors 


\begin{tabular}{lccc}
\hline \multicolumn{1}{c}{ Statistics } & Optimal value & Estimated values & Status of Index \\
\hline Chi-square indicators & The less is better & 849,981 & - \\
P-value & $>0.05$ & 0.000 & Not fitted \\
Relative Chi-square & $>2 ;<5$ & 2,168 & Fitted \\
CFI & $>0.9$ & 0.925 & Fitted \\
NFI & $>0.9$ & 0.921 & Fitted \\
IFI & $>0.9$ & 0.897 & Fitted \\
PCFI & $>0.6$ & 0.704 & Fitted \\
RMSEA & $<0.05 ;<0.08$ & 0.077 & Fitted \\
\hline
\end{tabular}

Table IV. Goodness of fit indices obtained from the study model

CFI = Comparative Fit Index; IFI = Incremental Fit Index; NFI = Normed Fit Index; PCFI = Parsimony-adjusted Comparative Fit Index; RMSEA = Root Mean Square Error of Approximation

\begin{tabular}{lccccc}
\hline \multicolumn{1}{c}{ Dimension } & $\begin{array}{c}\text { Nonstandard } \\
\text { coefficient }\end{array}$ & $\begin{array}{c}\text { Standard } \\
\text { parameter }\end{array}$ & Standard error & Test statistic & P-value \\
\hline Planning & 0.121 & 0.400 & 0.038 & 3.155 & 0.002 \\
Organization & 0.059 & 0.145 & 0.036 & 1.638 & 0.101 \\
Communication and information & 0.160 & 0.752 & 0.049 & 3.279 & 0.001 \\
Service speed & 0.486 & 0.765 & 0.064 & 7.574 & $* *$ \\
Human resources & 0.126 & 0.935 & 0.057 & 2.204 & 0.027 \\
\hline
\end{tabular}

Table V. The effect sizes of the model of confirmatory factor analysis of factors affecting the establishment of pre-hospital emergency bases

The initial eigenvalue of the first factor was 4.542 and that of the fifth factor was 2.042. In total, these factors explained $56.658 \%$ of the variance, where the first factor with $16.627 \%$ had the highest contribution and the fifth factor with $7.246 \%$ had the lowest contribution in explaining the variance. In Table III, the factor of physical accessibility proportionate to the population size has the highest mean scores, and the factor of using GIS has the lowest mean scores from the viewpoint of the operational personnel. The factors were identified later in the Varimax rotation. The results showed the internal consistency of the components and compatibility of each component with the establishment of prehospital emergency bases. Then, confirmatory factor analysis was employed for evaluating the goodness of fit of each factor and general validation of the model, and the model was used (see Table IV).

Using confirmatory factor analysis, it was found that there are five main factors in the mechanism of the Pre-hospital Emergency Bases Establishment questionnaire, including planning (with 10 variables), service speed (with 6 variables), communication and information (with 5 variables), organization (with 5 variables) and human resources (with 4 variables). All components confirming the original model were proposed. The calculated effect sizes for components of human resources, service speed, and communication and information system were $0.935,0.775$, and 0.752 , respectively. The values show that these components have more weight than the other ones. In order to study different components of establishment of Emergency bases and to determine the effect of these components on each other, multiple regression was used. The highest parameter estimation in this model was assigned to the component of human resources (0.935), which had a significant correlation with other components. The minimum parameter estimation was related to organization $(0.41)$, which had no significant correlation with other components. Findings of Table V indicate the significance level of the various factors' coefficients.

According to the results obtained from the previous steps, five final factors were identified for designing the model; as a result, a model with five themes was designed.

"Emergency as an independent organization" with the coefficient of 0.816 was the most effective subcomponent. In the component of service speed, "population and accessibility proportionate to the population" had the highest factor loading as 0.761. In the human resources component, the "organizational row assignment" with the coefficient of 0.706 had the highest factor loading. In the component of organization, the subcomponent of "rules and regulations", with the coefficient of 0.761 had the most factor loading and, finally, in 


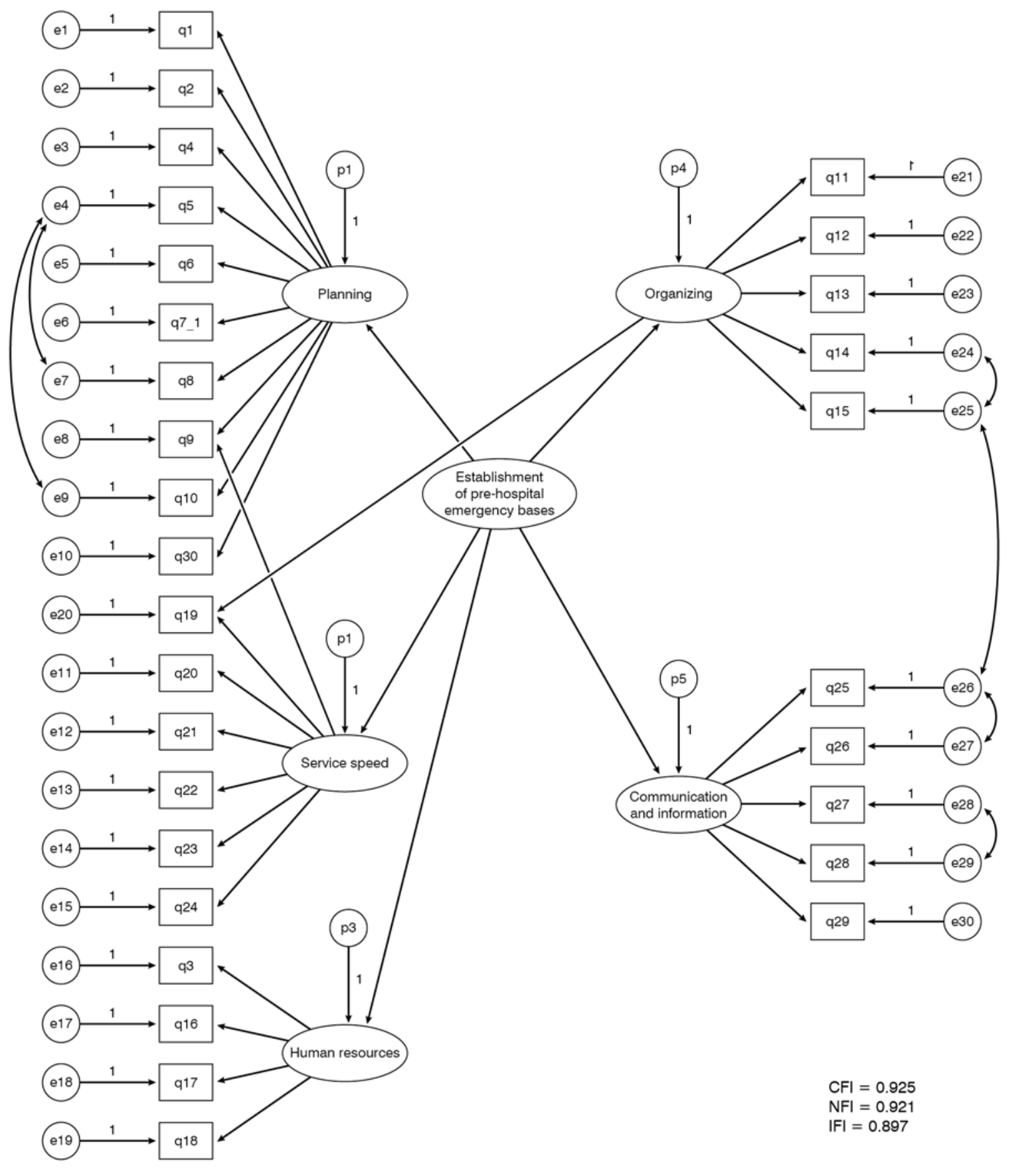

Figure 1. The fitted model based on the standard values

$\mathrm{CFI}=$ Comparative Fit Index; IFI = Incremental Fit Index; NFI = Normed Fit Index; PCFI = Parsimony-adjusted Comparative Fit Index; RMSEA = Root Mean Square Error of Approximation

\begin{tabular}{llc}
\hline \multicolumn{1}{c}{ Components } & \multicolumn{1}{c}{ Subcomponents } & Factor loading \\
\hline Planning & $\begin{array}{l}\text { Establish an independent and } \\
\text { policy-making EMS organization }\end{array}$ & 0.816 \\
Service speed & $\begin{array}{l}\text { Physical accessibility proportionate } \\
\text { to the population size }\end{array}$ & 0.761 \\
$\begin{array}{l}\text { Communication } \\
\text { and information }\end{array}$ & Proper communication equipment & 0.782 \\
$\begin{array}{l}\text { Organizing } \\
\text { Human resources }\end{array}$ & $\begin{array}{l}\text { Rules and regulations } \\
\text { Assigning personnel rows for } \\
\text { employment of human resources }\end{array}$ & 0.761 \\
\hline
\end{tabular}

Table VI. Subcomponents with the highest factor loadings in the five extracted components the component of communication and information, the "communication equipment" subcomponent with the coefficient of 0.782 was the most factor loading factor (see Table VI).

The effect size and factor loading of every subcomponent on each of the components of the model of establishment of Emergency bases are presented in the following table. Table VII illustrates that the confirmed model reveals that the human resource component has the highest regression weight and has more significance in designing the model. 


\begin{tabular}{|c|c|c|c|c|}
\hline Component & $\begin{array}{l}\text { Size } \\
\text { effect }\end{array}$ & Code of the subcomponents related to each component & $\begin{array}{c}\text { Size } \\
\text { effect }\end{array}$ & $\begin{array}{l}\text { Factor } \\
\text { loading }\end{array}$ \\
\hline \multirow[t]{10}{*}{ Planning } & \multirow[t]{10}{*}{0.400} & q30 - Establishing an EMS Independent and Policy Making Organization & 0.340 & 0.816 \\
\hline & & q10 - Synchronization of logistic (technical and executive) and financial resources & 0.332 & 0.811 \\
\hline & & q9 - Integration of Pre-hospital and Hospital Emergencies & 0.163 & 0.773 \\
\hline & & q8 - Cooperation with government departments & 0.294 & 0.732 \\
\hline & & q7 - Joint Planning with Private Entities & 0.457 & 0.695 \\
\hline & & q6 - Using the capacity of charities and NGOs & 0.412 & 0.419 \\
\hline & & q5 - Financial and Budget Planning (allocation of credits and per capita) & 0.205 & 0.660 \\
\hline & & q4 - Planning for the preparation and utilization of the required equipment & 0.614 & 0.659 \\
\hline & & q2 - Operational planning of regional units & 0.603 & 0.610 \\
\hline & & Q1 - Pre-hospital emergency Policy Making Unit based on preparatory areas & 0.647 & 0.504 \\
\hline \multirow[t]{5}{*}{ Organization } & \multirow[t]{5}{*}{0.145} & $\begin{array}{l}\text { q15 - The existence of files for changing codes, mission statement system, office } \\
\text { and attendance register, equipment checklist }\end{array}$ & 0.822 & 0.565 \\
\hline & & q14 - Pre-hospital emergency standards and protocols & 0.805 & 0.613 \\
\hline & & q13 - Performing group work & 0.784 & 0.685 \\
\hline & & q12 - Existence of prescribing specific tasks & 0.725 & 0.567 \\
\hline & & q11 - Rules and regulations & 0.639 & 0.761 \\
\hline \multirow[t]{7}{*}{ Service speed } & \multirow[t]{7}{*}{0.765} & $\begin{array}{l}\text { q19- Construction of bases based on accidental areas and physical accessibility to } \\
\text { climatic features }\end{array}$ & 0.660 & 0.638 \\
\hline & & q20 - Attention to areas prone to natural disasters & 0.731 & 0.413 \\
\hline & & q21 - Physical accessibility proportionate to the population size & 0.750 & 0.761 \\
\hline & & q22 - Attention to the traffic density of the area & 0.680 & 0.733 \\
\hline & & q23 - Suitability of routes to the main roads & 0.480 & 0.603 \\
\hline & & q24 - Establishment of emergency airspace in severe areas & 0.284 & 0.481 \\
\hline & & q25 - Using GIS to record the incident address points & 0.289 & 0507 \\
\hline \multirow{4}{*}{$\begin{array}{l}\text { Communication } \\
\text { and information }\end{array}$} & \multirow[t]{4}{*}{0.752} & q26 - Proper communication equipment & 0.451 & 0.782 \\
\hline & & q27 - National and regional data control center & 0.746 & 0.590 \\
\hline & & q28 - Specified reporting format & 0.563 & 0.577 \\
\hline & & q29 - Online communication technology with operational units and message center & 0.425 & 0.710 \\
\hline \multirow{4}{*}{$\begin{array}{l}\text { Human } \\
\text { resources }\end{array}$} & \multirow[t]{4}{*}{0.935} & q18 - Academic Courses & 0.740 & 0.665 \\
\hline & & q17 - Systematic training of people, non-EMS rescuers, technicians, and physicians & 0.855 & 0.513 \\
\hline & & q16 - How to provide services by human resources based on service delivery models & 0.676 & 0.445 \\
\hline & & q3 - Attainment of personnel rows for employing human resources & 0.169 & 0.706 \\
\hline
\end{tabular}

Table VII. The effect size and factor loading of each subcomponent on each of the components of the model of establishment of prehospital emergency bases

\section{DISCUSSION}

According to the research results, the most important factors affecting the establishment of pre-hospital emergency bases are planning, communication and information, organization, time and speed of service, and human resources. In this regard, the findings of the studies done by Pakhareh et al. [13] and Van Rouen et al. [14] are very similar to the findings of the present study. Pakhareh et al. also identified human resource factor with the highest effect size as the most important factor in preparation and establishment of the pre-hospital emergency bases [13]. Moreover, Khankeh et al. [8] and Al- Shaqsi et al. [15] studied pre-hospital services and examined different dimensions of pre-hospital emergency management system, including management, organization, human resources, and communication. Their findings are also consistent with those of the present study. The results also indicate that among the ten subcomponents of planning, the creation of independent EMS organizations, logistic and financial resources, and joint planning with governmental organizations have the highest factor loadings and are the most important factors. These results are consistent with those of Bahrami et al. [1], Bayrami et al. [9] and Haghparast et al. [16] studies. But in their study, Sharifani et al. [17] disagre with the organization independence in the field of medical emergencies and 
rejects the research findings in this regard. They believe that this independence will impose huge costs on the government. In addition, they indicate that in terms of bureaucracy, a broad and long-term organization will be created, and the actual potentialities of universities may be lost with this disconnection. Erie et al. [18] also considered the participation of governmental organizations, including police and firefighting, in establishing important pre-hospital emergency bases. The study suggests that the achievement of the organizational goals, i.e. saving patients' lives, requires intra- and inter-organizational communication and coordination of important management components.

Communication facilities have been introduced as one of the effective components in the establishment of pre-hospital emergency bases. These results are consistent with those of Nasiripour et al. [19] and Moghaddasi et al. [20]. Edent et al. [21] introduced the key feature of the pre-hospital emergency medical communication system. Under the communication components in this research, the appropriate communication equipment has the highest weight, which is consistent with the results of Walderhaug et al. study [22] which shows that suitable communication and information systems can lead to quickly locating the accident and reducing response time. It also facilitates the collection and processing of information.

In the present study, the rules and regulations, as organizational subcomponents, had the highest factor loading. The results are consistent with the results of Bahadori et al. [3]. Weninger et al. [23], with his study in Austria, claimed the creation of rules related to the training of physicians as an important step in reaching integrated care. The public access law was presented in 2001. The existence of these codified rules prompted Austria to develop an advanced emergency system and put the entire country under control, which is due to the importance of this component in the establishment of pre-hospital emergency bases. Furthermore, in the interviews, the existence of deficits in standards as well as rules and regulations that prompted the subjective practices of emergency centers in the cities is regarded as one of the causes of this defect in the laws due to making the tasks of emergency centers insignificant in the view of the Deputy of Therapy in Medical Education Universities. In this study, among the 5 components, the least parameter estimation was related to organization, which did not have a significant correlation with other components. It seems that considering the following components of organization in this study, including task descriptions and recording the presence and absence of the staff, which was noted by the operational staff in the questionnaire, is related to the performance of the staff themselves and is not considered serious in the eyes of the staff. Therefore, the responses given by the operational staff did not consider this component important for the establishment of pre-hospital emergency bases. Accordingly, it is suggested that this component be considered by managers and supervisors in future in order to obtain correct information about it. The results were also confirmed by the study of Pakhareh et al. [13].

The research findings indicate also the effect of human resources on the establishment of pre-hospital emergency bases. These results are consistent with those of Rösler et al. [10] in Germany and in developing countries regarding the healthcare model. Healthcare in developing countries, such as Iran, which is traditional in nature, does not focuses on physician-oriented healthcare, but participation of the technicians in baselines can have a significant effect on the reduction of the mortality rate, which may consequently reduce the cost of diseases and disabilities. Rösler's study in the advanced country of Germany suggests that pre-hospital care has been improved by specialists and primary specialist therapies have been improved by physicians. This kind of care is tremendously effective. Studies in Iran show that lack of trained staff is a serious challenge. However, in recent years, with the development of university programs such as Emergency Medical Technicians and Medical Emergency, a suitable ground has been created for increasing human resources capacity.

Regarding the significance of the subcomponent of lack of organizational rows, the inability of the system to persuade the staff who has gained a few years of experience to stay is considered as one of the effective subcomponents on the establishment of pre-hospital emergency bases. The results are consistent with Erie's studies. The training of people and rescuers, staff, and physicians is considered as an important component that can lead to a significant decrease in the mortality rate. The results are also consistent with the study of Hassum et al. [24] conducted in northern Iraq and Cambodia.

In the component of service speed, attention was given to the floating population and physical accessibility proportional to the population size and traffic volume. Simons et al. [25] considered the comprehensive accessibility component, regardless of spatial location, in the establishment and functioning of pre-hospital emergency bases. His results confirm the findings of the present study. In Haghparast et al. [16] study, the accessibility component 
was investigated in three relevant indicators (number of ambulances, ambulance dispatching sites, and staff), which had a significant effect on reducing the mortality rate caused by road accidents. This result is consistent with those of the present study. However, Haghparast's study only examined the component of accessibility, while the present study also deals with other components [16].

Ali et al. [26] also deal with the distribution of facilities in accordance with the characteristics of each region and population. The results of this study indicated that paying attention to these subcomponents in the northern provinces of Iran, due to the floating population and the touristic nature of the region because of the beautiful nature, coastal sites, being located on the route of west to east of Iran, and having mountainous roads connecting to the capital of the country, should be highly considered by politicians and managers of Iran's medical emergency fields.

\section{CONCLUSION}

Setting up pre-hospital emergency bases is affected by several factors, such as planning, human resources, service speed, communication and information system, and organization. It is important to note that the model developed in this study is a multidimensional one whose dimensions should not be ignored. This means that for the establishment of pre-hospital emergency bases, all components obtained in this research should be considered. Particularly, human resources and service speed should receive more attention from policy makers and planners. According to the results of this study, the following suggestions are recommended: to increase the speed of service, access to databases should be based on population density. Independence of the organization should be guaranteed all over Iran. The presence of people, service providers, and related organizations in the committees should be strengthened. Some parts of the regulation of the comprehensive coverage plan for pre-hospital emergency services, including the allocation of an ambulance engine should be amended. Allocating taxes or paying some prevention costs to some organizations that contribute to the burden of disease and accidents in the community should be considered. In this research, the data were collected based on existing and available library resources, and some of the effective factors on the establishment of pre-hospital emergency bases in the study countries may not be found. This was one of the most important research limitations.

\section{Funding}

This article has been published without the support of sponsors.

Disclosure

The authors declare they have no competing financial interests concerning the topics of this article.

\section{REFERENCES}

1. Bahrami MA, Ranjbar Ezzatabadi M, Maleki A, et al. A Survey on the Yazd Pre-hospital Emergency Medical Services' Performance Assessment, 2009-2010. Tolooe Behdasht 2011; 9: 45-58

2. Iranian Census Center. Available at: https://www.amar.org.ir/ (last accessed August 2012)

3. Bahadori M. Prioritization of pre-hospital emergency service determinants influencing preparedness of Iranian. Iranian Journal of Critical Care Nursing 2011; 4: 73-8

4. Rafiee HR. Investigating the tasks and responsibilities of organizations involved in the education of Iran's traffic safety culture. Traffic Management Studies 2011; 24: 25-48

5. Siddiqui AA, Zafar H, Bashir SH. An audit of head trauma care and mortality. J Coll Physicians Surg Pak. 2004Mar;14(3):173-7

6. Hunyadi-Anticevic S. EMS system in Croatia. Resuscitation 2006; 68: 185-91; https://doi. org/10.1016/j.resuscitation.2005.09.011

7. Hajinabi K, Riahi L, Gholipour Varki H. The Relationship between Prehospital Time Indices and on-Scene Death Rate in Traffic Accidents in the 22 Regions of Tehran. Health Information Management 2014; 11: 353-61 
8. Al-Shaqsi S. Models of International Emergency Medical Service (EMS) Systems. OMJ 2010; 25: 320-3; https://doi.org/10.5001/omj.2010.92

9. Bairami R, Ebrahimipoor H, Rezazadeh A. Preschool hospitals of Mashhad (Qualitative study). Hospital〉s profile. International Journal of Pediatric 2017; 16: 81-8

10. Roessler M, Zuzan O. EMS systems in Germany. Resuscitation 2006; 68: 45-9; https://doi. org/10.1016/j.resuscitation.2005.08.004

11. Hisamuddin N, Hamzah MS, Holliman CJ. Prehospital emergency medical services in Malaysia. J Emerg Med 2007; 32: 415-21; https://doi.org/10.1016/j.jemermed.2006.08.021

12. Mohammadi JA, Tabibi SJ. Riahi L, et al. Financing approach in pre-hospital and hospital emergencies in Iran. Quarterly Journal of Healthcare Management 2017; 8: 67-81

13. Pakhere E, Razaeirad M, Tahmasebi B, et al. Ranking the Factors Affecting Readiness of Prehospital Emergency Care According to the Perspectives of Staff in Mazandaran Prehospital Emergency Services. Journal of Mazandaran University of Medical Sciences $2016 ; 25: 261-9$

14. VanRooyen MJ, Thomas TL, Clem KJ. International emergency medical services: assessment of developing prehospital systems abroad. J Emerg Med 1999; 17: 691-6; https:// doi.org/10.1016/S0736-4679(99)00065-7

15. Khankeh H, Alinia S, Masoumi G, et al. Prehospital services by focus on road traffic accidents: Assessment developed and developing countries. JHPM 2013; 2: 71-9

16. Bidgoli HH, Bogg L, Hasselberg M. Pre-hospital trauma care resources for road traffic injuries in a middle-income country a province based study on need and access in Iran. Injury 2011; 42: 879-84; https://doi.org/10.1016/j.injury.2010.04.024

17. Sharifani M, Tabibi, SJ. A comparative study of the emergency system in selected countries and providing a suitable model for Iran. Quarterly Journal of Healthcare Management 2000; 3: 145-75

18. Eri M, Jafari N, Kabir MJ, et al. Concept and Challenges of Delivering Preventive and Care Services in Prehospital Emergency Medical Service: A Qualitative Study. J Mazandaran Univ Med Sci 2015; 25: 42-57

19. Nasiripour A, Bahadori M, Tofighi SH, et al. Prehospital Emergency Performance in Iran. Critical care Nursing Journal 2008: 2: 139-43

20. Moghadasi H, Rabiei R, Mustafa Z. Pre-hospital Emergency Information System in America and England: a review. Payesh 2014; 13: 383-391

21. Adnet F, Lapostolle F. International EMS systems: France. Resuscitation 2004; 63: 7-9; https://doi.org/10.1016/j.resuscitation.2004.04.001

22. Walderhaug S, Meland PH, Mikalsen M, et al. Evacuation support system for improved medical documentation and information flow in the field. International Journal of Medical Informatics 2007; 77: 137-51; https://doi.org/10.1016/j.ijmedinf.2007.01.006

23. Weninger P, Hertza H, Mauritz W. International EMS. Austria. Resuscitation 2005; 65: 249-54; https://doi.org/10.1016/j.resuscitation.2005.03.006

24. Husum H, Gilbert M, Wisborg T. Training pre-hospital trauma care in low-income countries: the 'Village University' experience. Medical Teacher 2003; 25: 142-8, https://doi. org/10.1080/0142159031000092526

25. Symons P, Shuster M. International EMS Systems: Canada. Resuscitation 2004; 63: 119-22; https://doi.org/10.1016/j.resuscitation.2004.06.010

26. Ali J, Adam RU, Gana TJ, et al. Impact of the prehospital trauma life support programme in Trinidad and Tobago. West Indian Med J 1998; 47: 102-4 